\title{
Study of coordinated control method based on Generator Units share High-Voltage Variable Frequency Starting of the Pumped Storage Power Station
}

\author{
Mu Xianyong ${ }^{1, a}$, Yin Jiayue ${ }^{2, b}$,Wang Kunjie ${ }^{1, c}, \mathrm{He} \mathrm{Li}^{2, \mathrm{~d}}, \mathrm{He} \mathrm{Le}^{2, \mathrm{e}}, \mathrm{Li}$ Xiaoming ${ }^{2, f}$
}

${ }^{1}$ Hubei Bailianhe pumped storage co., LTD, Luotian, 438600, China;

${ }^{2}$ School of Electrical Engineering, Wuhan University, Wuhan, 430072, China)

a blhmxy@163.com, b1162484454@qq.com, c904863231@qq.com,

d1528859432@qq.com, enele@whu.edu.cn, fxmli@whu.edu.cn

\section{Keywords: Pumped Storage Power Station; Generator Units Start; Variable Frequency Start; Digital} Simulation.

Abstract. With the continuous expansion of grid, Pumped Storage Power Station in the protection of the role of the power system safe and economic operation is more and more prominent. Pumped Storage Units under the condition of the transformation from the generator operation mode to the electric operation mode, how to start to effectively limit the starting current in the electric operation mode, reduce disturbances on the grid and influence of power quality is the key technical problems of Pumped Storage Power Station operation. When generator units share high- voltage variable frequency starting of the Pumped Storage Power Station. There is a close relationship in the starting process between power grid and the influence size of auxiliary power system power quality and high-voltage frequency conversion device of SFC and the mode that high voltage transformer access to system power. In order to solve this problem, this paper will study of coordinated control method based on generator units share high-voltage variable frequency starting of the Pumped Storage Power Station, and a digital simulation was carried out to illustrate its validity and feasibility. The method has guiding significance for design and operation control to coordinated control method based on generator units share high-voltage variable frequency starting of the Pumped Storage Power Station.

\section{Introduction}

In our country, one of the typical configuration in Pumped Storage Power Station is equipped with a set of high voltage frequency conversion starter SFC. It starts the 4 units of $300 \mathrm{MW}$ reversible pumped storage unit. Units and the main transformer use unit connection. The two high voltage transformer take electricity from the main transformer low voltage side respectively, and provide two pieces of auxiliary power. And in a $500 \mathrm{KV}$ Voltage grade access to the power system. Because of the pumped storage units is high power excitation synchronous motor, During startup of generator units share high-voltage variable frequency starting device SFC. The condition is very complex, and to the power grid, power quality of the auxiliary power system will have prominent effect. So in this paper, in combination with the practice of the Pumped Storage Power Station, and the problem of generator units share high-voltage variable frequency starting is researched. Proposed coordinated control method based on generator units share high-voltage variable frequency starting of the Pumped Storage Power Station. And a digital simulation was carried out to illustrate its validity and feasibility.

\section{Analysis of the frequency starting process}

The principle of Static Frequency Converter soft start: The Static Frequency Converter through the control of the thyristor, it will drag the power into a frequency and amplitude that are gradually increased from zero to the rating voltage, it drags the unit to the machine starting ${ }^{[1]}$. When the unit speed to achieve synchronous speed, starting the same time process. When reaching the grid interconnection condition, exiting the inverter. 


\section{The operating characteristics of Static Variable Frequency Starting system}

The Static frequency Converter speed regulating device includes AC-DC-AC inverter, synchronous motor, field system, the device of rotor position detection, and control system ${ }^{[2]}$. The system structure of diagram is shown in Figure 1, and the job characteristics are as follows:

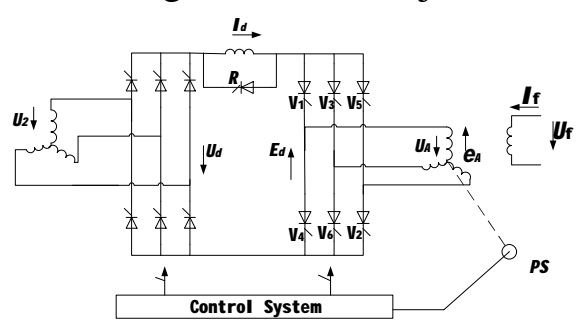

Figure 1. The structure of Variable Frequency Speed control system

(1) regulating characteristics

$$
\begin{aligned}
& U_{d}=2.34 U_{2} \cos a \\
& E_{d}=U_{d}-I_{d} R=K_{e} \Phi n \cos \left(\gamma_{0}-\frac{\mu}{2}\right) \cos \frac{\mu}{2} \\
& n=\frac{U_{d}-I_{d} R}{K_{e} \Phi \cos \left(\gamma_{0}-\frac{\mu}{2}\right) \cos \frac{\mu}{2}}
\end{aligned}
$$

In the formula 3, $R$ represents equivalent resistance of the main circuit, which is mainly by the thyristor conduction equivalent resistance, flat wave reactor of resistance and armature winding resistance $(\Omega), U_{2}$ represents Power grid voltage virtual value $(\Omega), U_{d}$ represents the average output voltage of rectifier bridge $(\mathrm{V}), E_{d}$ represents the average DC input voltage of inverter bridge $(\mathrm{V}), I_{d}$ represents DC bus average current(A), $\gamma_{0}$ represents advance overlap angle(Deg), $\mu$ represents commutation overlap angle(Deg), $a$ represents retardation angle of rectification(Deg), $K_{e}$ represents Electromotive Force, $\Phi$ represents The air gap magnetic flux of the machine $(\mathrm{Wb})$.

(2)torque characteristics

$$
T_{e}=K_{t} \Phi I_{d} \cos \left(\gamma_{0}-\frac{\mu}{2}\right) \cos \frac{\mu}{2}
$$

In the formula $4, K_{t}$ represents torque constant, $N_{k}$ represents winding circles.

(3) the mechanical characteristics

$$
n=\frac{U_{d}}{K_{e} \cos \left(\gamma_{0}-\frac{\mu}{2}\right) \cos \frac{\mu}{2}}-\frac{R}{K_{e} K_{t} \Phi^{2} \cos ^{2}\left(\gamma_{0}-\frac{\mu}{2}\right) \cos ^{2} \frac{\mu}{2}} T
$$

In the formula 5, $T$ represents torque-slip characteristic, $T=T_{e}-T_{l}, T_{l}$ represents load torque.

\section{The strategy of revolving speed current double closed-loop control}

During the unit starting, it needs to introduce revolving speed current double closed-loop control to achieve the control of the DC system current and rotating speed astatic regulation ${ }^{[3]}$.The working principle of double closed loop control starting is: When the units starting, revolving speed loop in the saturated state that does not play a role. At this time, it is mainly the inner current loop plays the role, adjusting the starting current to maintain maximum value, making speed rapid rise to the rate. When the units speed near the rate, the outer loop of speed feedback loop plays the main role, it can eliminate speed deviation at this time, and it can maintain a constant speed. It can be simulated analysis and verified on the principle of double closed-loop control under the MATLAB. The parameter selection of system simulation: Selecting the motor rated voltage and current of $220 \mathrm{~V} /$ $136 \mathrm{~A}$, the rated speed of motor is $750 \mathrm{r} / \mathrm{min}, C_{e}=0.25 \mathrm{~V} \mathrm{~min} / r$. Allow the multiple overload is $\lambda=1.5$, The magnification of thyristor rectifier is $K_{s}=40$, The total resistance of circuit is $R=0.5 \Omega$. The time constant is $T_{l}=0.03 s, T_{m}=0.18 \mathrm{~s}$. The coefficient of speed feedback is $a=0.007 \mathrm{~V} \mathrm{~min} / r$. The coefficient of current feedback is $\beta=0.05 \mathrm{~V} / \mathrm{A}$.

Using the above parameters, the design of rotating speed and current double closed-loop control 
simulation. The simulation model result is shown in Figure 2(a). It can be seen by the output curve of spin speed current double closed loop control, and after about $0.3 \mathrm{~s}$, the revolving speed current double closed-loop, the speed stability at the rated speed $750 \mathrm{r} / \mathrm{min}$. This shows that the double closed loop control has played a role. But there discovered by the results of simulation speed overshoot, and the overshoot reached $13 \%$. In order to solve phenomenon of excessive speed overshoot in the double closed loop control. It can be join a differential negative feedback link on the speed regulator. After that, the improved simulation results is shown in Figure 2(b).

The negative feedback link on the speed regulator in the simulation is 0.001 , After introducing differential negative feedback, speed can be achieved without overshoot, and stability in the value of $750 \mathrm{r} / \mathrm{min}$, This $13 \%$ relative to the original speed overshoot amount has improved significantly and improved, and it fully illustrates the effect of differential negative feedback.

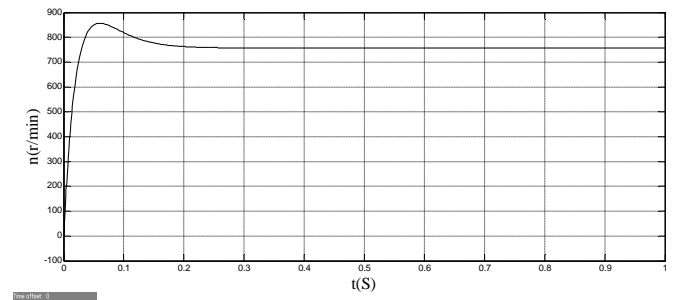

(a)

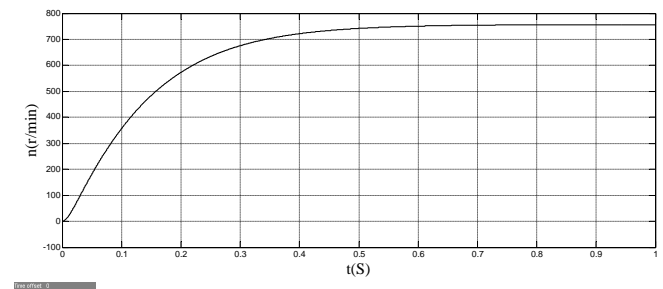

(b)

Figure 2 The simulation model and result of speed current double closed-loop control after improve

\section{Digital simulation of generator units variable frequency starting}

Based on the principle and control strategy of Pumped Storage Units. It can be modeled and simulated the variable frequency starting process of units by MATLAB ${ }^{[4,5]}$. The main circuit part mainly consists of three phase AC power, three phase transformer, rectifier bridge, filter DC reactor, inverter bridge, SFC output transformer, synchronous motor. Control module contains double closed loop module and speed current 12 pulse rectifier bridge trigger module. Pulse inverter bridge trigger logic module and the way the thyristor converter switch module. Because the MATLAB synchronous motor model can be directly output angle of rotor position and speed. By the use of rotor position angle and speed, and a given converter lead angle $\gamma_{0}$, inverter bridge thyristor trigger order can be allocated by writing Sfunction function. The output of speed current of the double closed loop can be acted as time delay of the rectifier bridge thyristor trigger signal. Rectifier bridge pulse trigger signal using Simulink own 12-pulse generator Synchronized 12-Pulse Generator module. When the rotational speed of the unit rose to $10 \%$ of rated speed, then at the beginning of the way into the thyristor switch controlled, chopper commutation into the back EMF commutation.

The model simulation parameters is according to the parameter of field device selection, as shown in Table 1.

Table 1 Model Simulation Parameter Design Table

\begin{tabular}{c|c}
\hline Device Name & Parameter Value \\
\hline Power supply & valid values of line voltage: $15.75 \mathrm{KV}$, resistance: $\mathrm{R}=0.5 \Omega$ \\
Step-down transformer & $\Delta / \Delta / Y: 15.75 / 2.5 / 2.5 \mathrm{KV} ; U_{k}=8 \%$ \\
Smoothing reactor & $0.083 \mathrm{H}$ \\
Step-up transformer & $\Delta / Y: 4.75 / 15.75 \mathrm{KV}, U_{k}=12 \%$ \\
Synchronous motors & $300 \mathrm{MW} ; 15.75 \mathrm{KV} ; \mathrm{n}=750 \mathrm{r} / \mathrm{min}$ \\
\hline
\end{tabular}

Simulation of synchronous motor pole number is 4 , rated speed is $750 \mathrm{r} / \mathrm{min}$, rated load excitation 
voltage is $280 \mathrm{~V}$, No-load rated power is $20 \mathrm{MVA}$, The simulation time is set to $14 \mathrm{~s}$, it use discrete algorithms, and start commutation mode switching in $1.1 \mathrm{~s}$, it reached the rated speed in $12 \mathrm{~s}$. During Units starting, rotor speed, electromagnetic simulation and terminal voltage are shown in Figure 3.

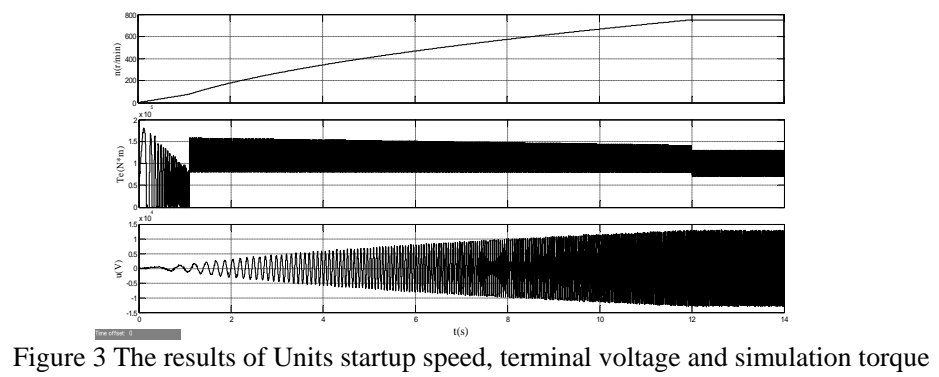

During units startup, SFC inputs in the voltage is shown in Figure 4(a) and current waveform simulation results is shown in Figure 4(b).

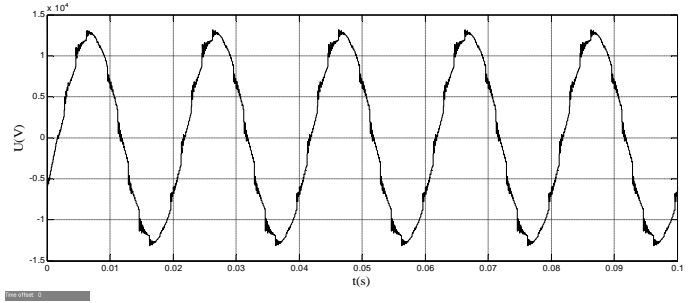

(a)

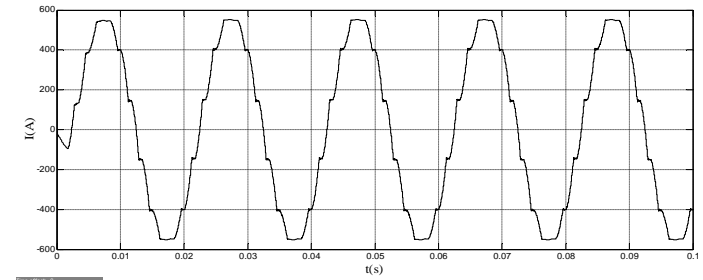

(b)

Figure 4 SFC inputs in the voltage and current

Analysis From the input of SFC voltage harmonic. Each harmonic content of the voltage as shown in Table 2.

Table 2 Statistics Of Each Voltage Harmonic Content

\begin{tabular}{cccccccc}
\hline \multicolumn{7}{c}{ Harmonic Content (\%) } & THD=5.27\% \\
\hline 1st & 100 & 10 th & 0.44 & 19 th & 0.31 & 28 th & 0.03 \\
2nd & 0.79 & 11 th & 3.02 & 20 th & 0.23 & 29 th & 0.05 \\
3rd & 0.69 & 12 th & 0.42 & $21 \mathrm{st}$ & 0.27 & 30 th & 0.02 \\
4th & 0.61 & 13 th & 2.38 & 22nd & 0.18 & $31 \mathrm{st}$ & 0.03 \\
5th & 0.62 & 14 th & 0.34 & 23rd & 1.15 & 32 nd & 0.02 \\
6th & 0.51 & 15 th & 0.38 & 24 th & 0.11 & 33 rd & 0.02 \\
7th & 0.51 & 16 th & 0.30 & 25th & 1.18 & 34 th & 0.07 \\
8th & 0.47 & 17 th & 0.37 & 26th & 0.06 & 35 th & 0.51 \\
9th & 0.49 & 18 th & 0.28 & 27th & 0.10 & 36 th & 0.09 \\
\hline
\end{tabular}

Compare with simulation and on site, SFC input voltage and current waveforms verify that the units variable frequency start control theory and technical correctness and authenticity from the simulation results. The results seen by the SFC inputs, there are a lot of voltage and current harmonics ${ }^{[6,7]}$. Voltage and current harmonics mainly containing $11,13,23,25$, which is due to the characteristics of high voltage variable frequency starter SFC phase 6 times(12-pulse wave) rectifying circuit, and it is same as characteristic harmonics of $2 K \pm 1$.

\section{Conclusions}

Conclude the analysis results of this paper, we can get the conclusions as follows:

(1) generator units share high-voltage variable frequency starting of the Pumped Storage Power Station, There is a close relationship in the starting process between power grid and the influence size of auxiliary power system power quality and high-voltage frequency conversion device of SFC and 
the mode that high voltage transformer access to system power. When the SFC and the high-voltage transformer power supply and units from the same main transformer. The starting process impact maximum on the grid and auxiliary power system quality, it must be avoided, When they are taken from different main transformer, coordinated control methods is precedence.

(2) High voltage variable frequency starter SFC is AC-DC-AC inverter device, it is the larger harmonic source in the inverter dragging. Different structures in SFC, and it is not the same affect on the boot process of the grid and auxiliary power system power quality, Using 3-phase rectifier inverter device, wherein the harmonic mainly containing 5,7,11,13. Using 6-phase rectifier inverter device, wherein the harmonic mainly containing $11,13,23,25$. In the case of excessive harmonic operation control can not be avoided, it must adopt an effective way to limit the harmonics, for example, harmonic isolation harmonic damping harmonic source side.

(3) Using MATLAB/Simulink to do a digital simulation for generator units share high-voltage variable frequency starting. The simulation results show that coordinated control method based on generator units share high-voltage variable frequency starting is correct.

\section{Acknowledgements}

This work was financially supported by Scientific and Technological Project of State Grid Xinyuan Company Ltd (5257001400S9).

\section{References}

[1] Guo Zhi, Sun Guoqiang, Xia Fujun. Huilong Pumped Storage Plant Electrical Design[J]. People's Yellow River, 2004,26 (06): 40-41.

[2] Wang Xifan. Main connection reliability studies of Power plant (a) the basic model and algorithms[J]. Xi'an Jiaotong University, 1990,24 (02): 31-40.

[3] Chen Shoulun. Pumped Storage Power Station - motor units (b)[J]. Electrical Engineering, 2001,04: 1-4.

[4] Zhou Shenyuan. AC and DC speed control system and MATLAB simulation[M]. Beijing: China Electric Power Press, 2007.

[5] Zhu Longji. Electrical Engineering and automatic control system of MATLAB simulation[M]. Jiangsu: China University of mining and Technology Press, 2014.

[6] Su Qinghua. Pumped Storage Plant SFC device harmonic analysis and suppression measures[D]. Zhejiang University, 2002.

[7] Zhou Jun. Several features of the SFC variable frequency starting on Pumped Storage Power Station[J]. Electric Power Automation Equipment, 2004,11: 99-101. 